\title{
Autologous Stem Cells Transplantation in Egyptian Patients with Liver Cirrhosis on Top of Hepatitis C Virus
}

\author{
Hoda Al Tayeb ${ }^{1}$, Ahmed El Dorry ${ }^{2}$, Nehad Amer ${ }^{1}$, Nadia Mowafy ${ }^{3}$, \\ Maha Zimaity ${ }^{1}$, Essam Bayoumy ${ }^{1}$, Shereen A.Saleh ${ }^{1}$ \\ Departments of ${ }^{1}$ Internal Medicine, ${ }^{2}$ Diagnostic and Interventional Radiology, and ${ }^{3}$ Clinical Pathology, \\ Faculty of Medicine, Ain Shams University, Cairo, Egypt
}

Background and Objectives: Use of pluripotent stem cells is an ideal solution for liver insufficiencies. This work aims is to evaluate the safety and feasibility of autologous stem cells transplantation (SCT) in Egyptian patients of liver cirrhosis on top of hepatitis $\mathrm{C}$ virus (HCV).

Subjects and Results: 20 patients with HCV induced liver cirrhosis were divided into 2 groups. Group I: included 10 patients with liver cirrhosis Child score $\geq 9$, for whom autologous stem cell transplantation was done using granulocyte colony stimulating factor (G-CSF) for stem cells mobilization. Separation and collection of the peripheral blood stem cells was done by leukapheresis. G-CSF mobilized peripheral blood mononuclear cells (G-CSF PB-MNCs) were counted by flow cytometry. Stem cell injection into the hepatic artery was done. Group II: included 10 patients with HCV induced liver cirrhosis as a control group. Follow up and comparison between both groups were done over a follow up period of 6 months. The procedure was well tolerated. Mobilization was successful and the total number of G-CSF PB-MNCs in the harvests ranged from $25 \times 10^{6}$ to $191 \times 10^{6}$. There was improvement in the quality of life, serum albumin, total bilirubin, liver enzymes and the Child-Pugh score of group I over the first two-three months after the procedure.

Conclusion: SCT in HCV induced liver cirrhosis is a safe procedure. It can improve the quality of life and hepatic functions transiently with no effect on the life expectancy or the fate of the liver cirrhosis.

Keywords: Autologous, HCV, Liver cirrhosis, Stem cells, Transplantation

\section{Introduction}

Liver cirrhosis is an ultimate outcome of irreversible damage of liver parenchyma by variety of pathological

Accepted for publication September 25, 2015, Published online November 30, 2015 Correspondence to Shereen A. Saleh

Department of Internal Medicine, Faculty of Medicine, Gastroenterology and Hepatology Unit, Ain Shams University, Lotfy El Sayed St., Abasseya Square, Cairo 11827, Egypt

Tel: +20-02-26131342, +20-02-24821485, Fax: +6837673-94070

E-mail: shereen_saleh2014@hotmail.com

(a) This is an open-access article distributed under the terms of the Creative Commons Attribution Non-Commercial License (http://creativecommons.org/ licenses/by-nc/4.0/), which permits unrestricted non-commercial use, distribution, and reproduction in any medium, provided the original work is properly cited. agents such as environmental toxins metabolic derangements and viral infection particularly hepatitis $C$ virus (HCV) and hepatitis B virus (HBV) (1).

Liver transplantation is increasingly done as a curative treatment worldwide (2). Despite this, $10 \%$ of those listed for transplantation will die while awaiting a donor liver (3). In addition, the risk of invasive surgical procedure, use of immune suppression, risk of disease recurrence and the extremely heavy cost for the remainder of life, calls for other therapeutic modalities (4).

Stem cells (SCs) are unspecialized cells that have two defining properties: the ability to differentiate into other cells and the ability to self regenerate (5). They are thought to act as progenitors with the ability to differentiate to hepatocytes (6). Bone marrow contains at least 
two kinds of stem cells, hematopoietic stem cells (HSCs) and mesenchymal stem cells or marrow stromal cells (MSCs) (7). HSC are continuously moving between the bone marrow and peripheral blood. This movement is critical for hematopoietic homeostasis and is hypothesized to contribute to homeostasis and repair in solid organs. HSC express a surface antigen known as stem cell antigen or $\mathrm{CD} 34^{+}$. They can be identified and counted by this property (8).

The use of pluripotent stem cells capable of differentiation into different cell lineages provides an optimistic solution for the problems associated with transplantation. They could allow for organ regeneration (1). Injection of bone marrow stem cells (BMSCs) directly into the liver was proved to be one of the preferred routes of administration (9).

This study was done to evaluate the safety, feasibility and outcome of stem cell transplantation (SCT) using autologous HSCs in Egyptian patients with HCV induced liver cirrhosis.

\section{Subjects and Methods}

This study was conducted on 20 patients with HCV induced liver cirrhosis, diagnosed by clinical, laboratory and ultrasound features of liver cirrhosis. They were collected from Internal Medicine Department and Hepatology outpatient clinic, Ain Shams University Hospitals over the whole period of a year. They were divided into two groups.

Group I: included 10 patients with liver cirrhosis on top of HCV. They were selected as late Child B and Child $\mathrm{C}$ with scores ranging from 9 to 12 according to Child-Pugh grading (10). Autologous Stem cell transplantation was done for patients of this group. One week after last attack of encephalopathy, haematemesis or infection had to pass before beginning of stem cell mobilization. These patients were on medical treatment including silymarin, diuretics and vitamin $\mathrm{K}$ support and continued on the same treatment after the stem cell transplantation (SCT). Changes in the doses of the diuretics were done according to the clinical assessment during the follow up period.

Group II: included 10 patients with liver cirrhosis on top of HCV. They were included as control group matching group I in age, sex and Child score. They continued on the conventional therapy they were on including silymarin, diuretics and vitamin $\mathrm{K}$, with no stem cell transplantation done for them.

Exclusion criteria: patients with liver tumors, heterogenous liver; history of other cancer; renal impairment (creatinine $>1.5 \mathrm{mg} / \mathrm{dl}$ ); other viral co-infection such as human immunodeficiency virus (HIV) or HBV; life expectancy less than 3 months; evidence of extrahepatic biliary diseases (e.g. presence of primary sclerosing cholangitis, or dilated common bile duct on ultrasound); presence of hepatic, portal, or splenic vein thrombosis on Doppler ultrasound; presence of severe co morbid diseases (e.g. severe renal, respiratory, or cardiac disease) and inability to give informed consent were excluded from the study.

\section{All patients of both groups were subjected to the following}

Detailed history taking and full clinical examination including: body weight, body mass index (BMI), abdominal girth, vital data, general and abdominal examination.

Laboratory investigations including: hepatic profile including total proteins, serum albumin, total bilirubin, direct bilirubin, aspartate transaminase (AST), alanine transaminase ALT, Alkaline phosphatase, gamma glutamyltransferase $(\gamma \mathrm{GT})$; bleeding profile including prothrombin time (PT), international normalized ratio (INR), partial thromboplastin time (PTT); complete blood picture and platelet count; renal functions and electrolytes including creatinine, blood urea nitrogen (BUN), sodium (Na) and potassium (K); viral markers and serology including hepatitis B surface antigen (HBsAg), HIV antibody, HCV antibody by enzyme-linked immunosorbent assay (ELISA), and HCV ribonucleic acid (RNA) by polymerase chain reaction (PCR), and $\alpha$-fetoprotein level (AFP), done by standard laboratory tests.

Abdominal ultrasound with assessment of liver parenchymal echogenicity, focal lesions, liver size, spleen size, portal vein diameter and the presence and severity of ascites (mild, moderate and massive). Equipment used: Hitachi, EUB-5500.

The above investigations were done for the patients of both groups at beginning of the study and were followed up after 1, 3 and 6 months for both groups. Follow up after 15 days after SCT was additionally done for patients of group I.

Upper gastrointestinal endoscopy: for detection of esophageal varices and assessment of their grade was done at the beginning of the study and was followed after 3 months for patients of both groups.

Statistical analysis of the results was done using: Wilcoxon Signed Ranks test to compare the results of patients of Group I before and after the SCT, and Mann Whitney test to compare between the results of the two groups. These two statistical tests are specific for small numbered samples. 


\section{SCT for patients of Group I was done in the following steps}

Stem cells Mobilization: the peripheral blood HSC count in normal subjects under un-stimulated conditions is very low $(<0.05 \%$ of the white blood cells). Granulocyte-colony stimulating factor (G-CSF) can mobilize a large number of HSC from the bone marrow (BM) into the circulation (15- to 35 fold following $4 \sim 5$ days of administration). Stem cells mobilization for patients of Group I was done by giving them G-CSF. We used GeneLeukim $^{\circledR}$ subcutaneous injections (Filgrastim $300 \mu \mathrm{g} / \mathrm{ml} / \mathrm{vi}$ al), in the dose of $10 \mu \mathrm{g} / \mathrm{kg} /$ day for 4 consecutive days. Another dose of $300 \sim 600 \mu \mathrm{g}$ was given to the patients on the $5^{\text {th }}$ day 3 hours before the session of leukapheresis.

Leukapheresis: separation and collection of the peripheral blood stem cells was done in the bone marrow transplantation unit (BMT unit) (Ain Shams University hospital), on the ${ }^{5 \text { th }}$ day of G-CSF administration using special mononuclear cell $(\mathrm{MNC})$ processing machine separator (COBE Spectra Apheresis System, Gambro BCT). Processing of two times the patient's blood volume was done over a period of $3 \sim 4$ hours at a rate of $40 \sim 80 \mathrm{ml} / \mathrm{min}$. In all patients, placement of a double lumen central venous apheresis catheter was necessary. Blood withdrawn from the patient through the access line is mixed with anticoagulant acid-citrate-dextrose-A(ACD-A) and pumped into the centrifuge channel. ACD-A was administered in a ratio of $1 \mathrm{~cm}$ ACD: $12 \mathrm{~cm}$ blood for prevention of extracorporeal clotting. This required oral and parentral calcium bicarbonate administration to avoid development of citrate reactions in the form of muscle cramps due to hypocalcemia. Blood pressure and heart rate monitoring were done before, during and after the session of leukapheresis.

Assessment of Stem Cells: upon completion of the stem cell collection, an aliquot is taken from the apheresis bag. The total nucleated cells in this aliquot are counted on an electronic blood cell counter and the percentage of G-CSF mobilized peripheral blood mononuclear cells (G-CSF PB-MNCs) is obtained by flow cytometric analysis. The total number of stem cells in the harvest is calculated by multiplying the percentage of G-CSF PB-MNCs obtained by flow cytometry $x$ the number of nucleated cells obtained by electronic cell counting and $x$ the final volume in the apheresis bag which ranged from 140 200 cc in our study. The number of stem cells in the harvests of the patients in our study ranged from $25 \times 1^{06}$ to $191 \times 1^{06}$. Follow up of platelets count and splenic size by ultrasound after stem Cells mobilization by G-CSF was done.
Stem cells injection: was performed into the hepatic artery in the following steps: after local anesthesia, puncture of right femoral artery was performed. Simon catheter advanced into the descending aorta, and catheterization of celiac axis and then hepatic artery was performed. The mean duration of catheterization was 10 minutes (range: $5 \sim 15 \mathrm{~min}$ ). Nonionic low osmolal radiocontrast agent was used to visualize the hepatic artery. Then the stem cells in the apheresis bag were transfused to the hepatic artery as equal aliquots of $50 \mathrm{~mL}$, taking an average time of 20 minutes. After that, the catheter was flushed with $10 \mathrm{cc}$ of normal saline and the procedure was finished. After the stem cell infusion the catheter was removed. The procedure was done in the Interventional Radiology Department, Ain Shams University. All the patients received fresh frozen plasma transfusion before and after the SCs injection due to prolonged prothrombin time.

The patients were kept in hospital under medical observation for 48 hours after which they were discharged. Following of their clinical, biochemical, radiological outcomes was performed after 15 days, 1 month, 3 months and 6 months after the SCT procedure. Parallel follow up of patients of Group $\Pi$ after 1 month, 3 months and 6 months was done.

The follow up of patients of both groups involved assessment of the quality of life, observation of the changes in hepatic biochemical profile, Child score, liver size or amount of ascites by ultrasound and body weight, development of any complications in relation to the procedure and occurrence of major side effects such as: renal failure, worsening hepatic decompensation, progressive elevation in the serum AFP, or development of liver mass in the ultrasound.

Written consent was granted in all cases and the study was approved by the ethical committee of Ain Shams University.

\section{Results}

This study was conducted on 20 patients with HCV induced liver cirrhosis who were divided into 2 Groups.

Group I: included 10 patients who received autologous SCT. They were male patients (100\%). Their ages ranged from $45 \sim 55$ years with a mean of $(49.20 \pm 3.27)$. Their Child-Pugh score ranged from 9 to 12 before procedure.

Group II: included another 10 patients of liver cirrhosis as a control group. Patients of this group were male patients $(100 \%)$. Their ages ranged from $45 \sim 54$ years with a mean of (49.20 \pm 3.27$)$. Their Child Pugh score range was from $9 \sim 12$. There was no statistical significant differences 
between the two groups regarding the age, sex, BMI or Child score.

Regarding the safety and feasibility of the SCT procedure, all the patients tolerated the treatment protocol well without any major complications or side effects related to the procedure. In particular, there was no bleeding, hemodynamic instability, infection or significant deterioration in liver function after the procedure. There were no cases of hepatorenal syndrome, and injection of the stem cells into the hepatic artery did not result in any thrombotic episode or bleeding.

The main adverse reactions related to G-CSF use noticed in the patients were the low grade fever, musculoskeletal pain, fatigue and itching for which oral paracetamol was given that improved the fever and the musculoskeletal pain. The other symptoms were mild and well tolerated and disappeared with discontinuation of the drug. Although, one patient developed mild hepatic precoma in the form of minimal flapping tremors on the $3^{\text {rd }}$ day of mobilization, he improved on anticoma measures (enema/6 houres, metronidazol \& lactulose) that didn't require stoppage of the SC transplantation. All the patients underwent successful leukapheresis sessions with no complications except for mild circumoral numbness to mild to moderate muscle cramps only in one patient which were handled by increasing the rate of calcium infusion and decreasing the rate of blood processing.

On comparing the clinical, laboratory and sonographic parameters of group I patients before and after the SCT there were statistically significant differences regarding:

- The serum albumin after 15 days and 1 month after the SCT with p-value $<0.05$ (Table 1).

- The total bilirubin after 1 month after the SCT with p-values $<0.05$ (Table 2)

- The $\gamma$ GT after 1 and 3 months of the SCT with p-values $<0.05$ (Table 3)

- The size of the spleen after 3 months of the SCT with p-values $<0.05$ (Table 4).

The Child score after 1 month after the SCT (p-values $<0.05$ ), with decrease in the mean of Child score from

Table 1. Comparisons regarding the serum albumin

\begin{tabular}{|c|c|c|c|c|c|c|c|c|c|c|}
\hline \multirow{2}{*}{ Groups } & & \multicolumn{5}{|c|}{ Albumin (g/dl) } & \multicolumn{4}{|c|}{ Wilcoxon signed ranks test ( $\mathrm{p}$-value) } \\
\hline & & T0 & T1 & T2 & T3 & T4 & P1 & P2 & P3 & P4 \\
\hline \multirow[t]{2}{*}{ Group I } & Mean & 2.417 & 2.700 & 2.800 & 2.550 & 2.467 & $0.043^{*}$ & $0.043 *$ & 0.399 & 0.686 \\
\hline & $\pm \mathrm{SD}$ & 0.519 & 0.420 & 0.518 & 0.404 & 0.388 & & & & \\
\hline \multirow[t]{2}{*}{ Group II } & Mean & 2.740 & & 2.520 & 2.320 & 2.180 & & 0.066 & $0.043 *$ & $0.041 *$ \\
\hline & $\pm \mathrm{SD}$ & 0.261 & & 0.311 & 0.471 & 0.390 & & & & \\
\hline \multirow{2}{*}{$\begin{array}{l}\text { Mann- } \\
\text { Whitney Test }\end{array}$} & Z & -0.744 & & -1.189 & -0.739 & -1.226 & & & & \\
\hline & p-value & 0.457 & & 0.234 & 0.460 & 0.220 & & & & \\
\hline
\end{tabular}

T0 (Time 0): before SCT, T1 (Time 1): after 15 days after SCT, T2 (Time 2): after 1 month after SCT T3 (Time 3): after 3 months after SCT, T4 (Time 4): after 6 months after SCT, $\mathrm{P}_{1}$ : comparison after 15 days. $\mathrm{P}_{2}$ : comparison after 1 month, $\mathrm{P}_{3}$ : comparison after 3 months, $\mathrm{P}_{4}$ : comparison after 6 months.

*Significant, SD: standard deviation.

Table 2. Comparisons regarding the total bilirubin

\begin{tabular}{|c|c|c|c|c|c|c|c|c|c|c|}
\hline \multirow{2}{*}{ Groups } & & \multicolumn{5}{|c|}{ Total Bilirubin (mg/dl) } & \multicolumn{4}{|c|}{ Wilcoxon signed ranks test ( $p$-value) } \\
\hline & & T0 & T1 & $\mathrm{T} 2$ & T3 & $\mathrm{T} 4$ & P1 & P2 & P3 & P4 \\
\hline \multirow[t]{2}{*}{ Group I } & Mean & 3.883 & 3.200 & 2.517 & 3.333 & 3.300 & 0.400 & $0.043^{*}$ & 0.249 & 0.343 \\
\hline & $\pm \mathrm{SD}$ & 1.486 & 1.375 & 0.768 & 1.487 & 1.889 & & & & \\
\hline \multirow[t]{2}{*}{ Group II } & Mean & 3.540 & & 3.260 & 3.340 & 4.760 & & 0.684 & 0.893 & 0.138 \\
\hline & $\pm \mathrm{SD}$ & 1.988 & & 1.057 & 0.586 & 1.494 & & & & \\
\hline \multirow{2}{*}{$\begin{array}{l}\text { Mann- } \\
\text { Whitney Test }\end{array}$} & $\bar{Z}$ & -0.737 & & -1.464 & -1.009 & -1.376 & & & & \\
\hline & p-value & 0.461 & & 0.143 & 0.313 & 0.169 & & & & \\
\hline
\end{tabular}

T0 (Time 0): before SCT, T1 (Time 1): after 15 days after SCT, T2 (Time 2): after 1 month after SCT, T3 (Time 3): after 3 months after SCT, T4 (Time 4): after 6 months after SCT, $\mathrm{P}_{1}$ : comparison after 15 days, $\mathrm{P}_{2}$ : comparison after 1 month, $\mathrm{P}_{3}$ : comparison after 3 months, $\mathrm{P}_{4}$ : comparison after 6 months.

*Significant, SD: standard deviation. 
Table 3. Comparisons regarding the gamma glutamyle transferase ( $\gamma$ GT)

\begin{tabular}{|c|c|c|c|c|c|c|c|c|c|c|}
\hline \multirow{2}{*}{ Groups } & \multirow{2}{*}{1} & \multicolumn{5}{|c|}{$\gamma \mathrm{GT}(\mathrm{mg} / \mathrm{dl})$} & \multicolumn{4}{|c|}{ Wilcoxon signed ranks test (p-value) } \\
\hline & & T0 & T1 & $\mathrm{T} 2$ & T3 & $\mathrm{T} 4$ & $\mathrm{P} 1$ & P2 & P3 & P4 \\
\hline \multirow[t]{2}{*}{ Group I } & Mean & 29.000 & 25.000 & 20.833 & 20.667 & 22.000 & 0.345 & $0.027^{*}$ & $0.027^{*}$ & 0.080 \\
\hline & $\pm \mathrm{SD}$ & 11.189 & 6.841 & 5.307 & 5.317 & 6.099 & & & & \\
\hline \multirow{2}{*}{ Group II } & Mean & 29.600 & & 28.400 & 29.800 & 33.200 & & \multirow{2}{*}{0.498} & \multirow{2}{*}{0.500} & \multirow{2}{*}{0.345} \\
\hline & $\pm \mathrm{SD}$ & 5.505 & & 4.879 & 9.011 & 3.347 & & & & \\
\hline Mann- & Z & -1.009 & & -1.930 & -1.376 & -2.476 & & & & \\
\hline Whitney Test & p-value & 0.313 & & 0.054 & 0.169 & $0.013 *$ & & & & \\
\hline
\end{tabular}

T0 (Time 0): before SCT, T1 (Time 1): after 15 days after SCT, T2 (Time 2): after 1 month after SCT, T3 (Time 3): after 3 months after SCT, T4 (Time 4): after 6 months after SCT, $\mathrm{P}_{1}$ : comparison after 15 days, $\mathrm{P}_{2}$ : comparison after 1 month, $\mathrm{P}_{3}$ : comparison after 3 months, $\mathrm{P}_{4}$ : comparison after 6 months.

*Significant; SD: standard deviation.

Table 4. Comparisons regarding the size of the spleen

\begin{tabular}{|c|c|c|c|c|c|c|c|c|c|c|}
\hline & & \multicolumn{5}{|c|}{ Spleen size $(\mathrm{cm})$} & \multicolumn{4}{|c|}{ Wilcoxon signed ranks test ( $p$-value) } \\
\hline & & T0 & $\mathrm{T} 1$ & $\mathrm{~T} 2$ & T3 & T4 & P1 & $\mathrm{P} 2$ & P3 & P4 \\
\hline \multirow[t]{2}{*}{ Group I } & Mean & 20.033 & 18.583 & 18.333 & 18.667 & 19.500 & 0.080 & 0.075 & $0.043^{*}$ & 0.400 \\
\hline & $\pm \mathrm{SD}$ & 2.437 & 2.836 & 2.960 & 2.160 & 2.429 & & & & \\
\hline \multirow[t]{2}{*}{ Group II } & Mean & 16.340 & & 16.140 & 16.300 & 16.520 & & 0.285 & 0.892 & 0.786 \\
\hline & $\pm \mathrm{SD}$ & 3.091 & & 2.872 & 2.110 & 2.013 & & & & \\
\hline Mann- & Z & -1.738 & & -1.278 & -1.566 & -1.742 & & & & \\
\hline Whitney Test & $p$-value & 0.082 & & 0.201 & 0.117 & 0.081 & & & & \\
\hline
\end{tabular}

T0 (Time 0): before SCT, T1 (Time 1): after 15 days after SCT, T2 (Time 2): after 1 month after SCT, T3 (Time 3): after 3 months after SCT, T4 (Time 4): after 6 months after SCT, $\mathrm{P}_{1}$ : comparison after 15 days, $\mathrm{P}_{2}$ : comparison after 1 month, $\mathrm{P}_{3}$ : comparison after 3 months, $\mathrm{P}_{4}$ : comparison after 6 months.

*Significant; SD: standard deviation.

Table 5. Comparisons regarding the Child-Pugh score

\begin{tabular}{|c|c|c|c|c|c|c|c|c|c|c|}
\hline \multirow{2}{*}{ Groups } & & \multicolumn{5}{|c|}{ Child Sore } & \multicolumn{4}{|c|}{ Wilcoxon signed ranks test ( $p$-value) } \\
\hline & & T0 & $\mathrm{T} 1$ & $\mathrm{~T} 2$ & T3 & T4 & P1 & $\mathrm{P} 2$ & P3 & P4 \\
\hline \multirow[t]{2}{*}{ Group I } & Mean & 10.500 & 10.000 & 9.667 & 10.000 & 10.833 & 0.257 & $0.025^{*}$ & 0.453 & 0.317 \\
\hline & $\pm S D$ & 1.049 & 1.549 & 1.366 & 1.673 & 1.169 & & & & \\
\hline \multirow[t]{2}{*}{ Group II } & Mean & 10.200 & & 10.800 & 11.400 & 12.600 & & 0.083 & $0.034^{*}$ & $0.042 *$ \\
\hline & $\pm \mathrm{SD}$ & 1.304 & & 1.095 & 1.517 & 2.302 & & & & \\
\hline \multirow{2}{*}{$\begin{array}{l}\text { Mann- } \\
\text { Whitney Test }\end{array}$} & $\bar{Z}$ & -0.471 & & -1.551 & -1.484 & -1.215 & & & & \\
\hline & p-value & 0.638 & & 0.121 & 0.138 & 0.224 & & & & \\
\hline
\end{tabular}

T0 (Time 0): before SCT, T1 (Time 1): after 15 days after SCT, T2 (Time 2): after 1 month after SCT, T3 (Time 3): after 3 months after SCT, T4 (Time 4): after 6 months after SCT, $\mathrm{P}_{1}$ : comparison after 15 days, $\mathrm{P}_{2}$ : comparison after 1 month, $\mathrm{P}_{3}$ : comparison after 3 months, $\mathrm{P}_{4}$ : comparison after 6 months.

*Significant; SD: standard deviation.

$(10.5 \pm 1.05)$ to $(9.7 \pm 1.4)$ after 1 month, and maintenance of the mean Child score around 10 over the follow up period (Table 5).

On the other hand there were none significant differences regarding the body weight, abdominal girth, total proteins, prothrombin time, partial thromboplastin time, direct bilirubin, AST (Table 6), ALT, alkaline phosphatase, creatinine, BUN, Na, K, total leukocyte count (TLC), hemoglobin $(\mathrm{Hg})$, platelets, liver size, portal vein diameter, amount of the ascites, AFP and grades of esophageal 
Table 6. Comparisons regarding the liver enzyme aspartate aminotransferase (AST)

\begin{tabular}{|c|c|c|c|c|c|c|c|c|c|c|}
\hline \multirow{2}{*}{ Groups } & & \multicolumn{5}{|c|}{ AST (U/L) } & \multicolumn{4}{|c|}{ Wilcoxon signed ranks test ( $p$-value) } \\
\hline & & T0 & $\mathrm{T} 1$ & $\mathrm{~T} 2$ & T3 & $\mathrm{T} 4$ & P1 & P2 & P3 & P4 \\
\hline \multirow[t]{2}{*}{ Group I } & Mean & 91.500 & 63.167 & 62.833 & 66.833 & 78.167 & 0.249 & 0.249 & 0.463 & 0.528 \\
\hline & $\pm \mathrm{SD}$ & 65.717 & 20.074 & 27.257 & 17.175 & 35.645 & & & & \\
\hline \multirow[t]{2}{*}{ Group II } & Mean & 131.800 & & 108.000 & 89.200 & 82.400 & & 0.080 & 0.080 & 0.080 \\
\hline & $\pm \mathrm{SD}$ & 49.857 & & 29.690 & 26.696 & 23.093 & & & & \\
\hline \multirow{2}{*}{$\begin{array}{l}\text { Mann- } \\
\text { Whitney Test }\end{array}$} & Z & -1.095 & & -2.008 & -1.372 & -0.730 & & & & \\
\hline & p-value & 0.273 & & $0.045^{*}$ & 0.170 & 0.465 & & & & \\
\hline
\end{tabular}

T0 (Time 0): before SCT, T1 (Time 1): after 15 days after SCT, T2 (Time 2): after 1 month after SCT, T3 (Time 3): after 3 months after SCT, T4 (Time 4): after 6 months after SCT, $\mathrm{P}_{1}$ : comparison after 15 days, $\mathrm{P}_{2}$ : comparison after 1 month, $\mathrm{P}_{3}$ : comparison after 3 months, $\mathrm{P}_{4}$ : comparison after 6 months.

*Significant; SD: standard deviation.

Table 7. Comparisons regarding the liver enzyme alanine aminotransferase (ALT)

\begin{tabular}{|c|c|c|c|c|c|c|c|c|c|c|}
\hline \multirow{2}{*}{ Groups } & & \multicolumn{5}{|c|}{$\operatorname{ALT}(\mathrm{U} / \mathrm{L})$} & \multicolumn{4}{|c|}{ Wilcoxon signed ranks test ( $p$-value) } \\
\hline & & T0 & $\mathrm{T} 1$ & $\mathrm{~T} 2$ & T3 & T4 & P1 & P2 & P3 & P4 \\
\hline \multirow[t]{2}{*}{ Group I } & Mean & 57.667 & 33.667 & 34.333 & 35.333 & 48.667 & 0.340 & 0.345 & 0.595 & 0.144 \\
\hline & $\pm \mathrm{SD}$ & 53.958 & 12.372 & 15.462 & 14.334 & 37.882 & & & & \\
\hline \multirow[t]{2}{*}{ Group II } & $\bar{M}$ Mean & 105.400 & & 85.200 & 70.000 & 59.600 & & 0.080 & 0.080 & 0.080 \\
\hline & $\pm \mathrm{SD}$ & 36.281 & & 19.665 & 20.137 & 21.801 & & & & \\
\hline \multirow{2}{*}{$\begin{array}{l}\text { Mann- } \\
\text { Whitney Test }\end{array}$} & Z & -1.643 & & -2.568 & -2.395 & -0.825 & & & & \\
\hline & p-value & 0.100 & & $0.010^{*}$ & $0.017^{*}$ & 0.409 & & & & \\
\hline
\end{tabular}

T0 (Time 0): before SCT, T1 (Time 1): after 15 days after SCT, T2 (Time 2): after 1 month after SCT, T3 (Time 3): after 3 months after SCT, T4 (Time 4): after 6 months after SCT, $\mathrm{P}_{1}$ : comparison after 15 days $\mathrm{P}_{2}$ : comparison after 1 month, $\mathrm{P}_{3}$ : comparison after 3 months, $\mathrm{P}_{4}$ : comparison after 6 months.

*Significant; SD: standard deviation.

varices.

Comparison between the two groups regarding the different parameters showed statistically significant differences regarding:

- The AST after 1 month of the follow up period with lower mean and standard deviation in the patients of Group I and $\mathrm{p}$ value $<0.05$ (Table 6)

- The ALT after 1 and 3 months of the follow up period with lower mean and standard deviation in the patients of Group I and p value $<0.05$ (Table 7).

- $\gamma$ GT level after 6 month of the follow up period with $\mathrm{p}$ value $<0.05$ (Table 3 ).

None significant differences between the two groups were noted regarding total proteins, serum albumin, total bilirubin, direct bilirubin, alkaline phosphatase, PT, PTT, creatinine, BUN, Na, K, TLC, Hg, platelets count, AFP, liver size, portal vein diameter, size of the spleen, amount of the ascites, grades of esophageal varices and death rate (Table 8). Although significant difference regarding the Child score between both groups was not found statisti-
Table 8. Comparison between the two groups regarding the death rate over the first year after the SCT

\begin{tabular}{llrcr}
\hline & & \multicolumn{3}{c}{ Death } \\
\cline { 3 - 5 } & & Alive & Died & Total \\
\hline \multirow{2}{*}{ Group I } & $\mathrm{N}$ & 5 & 5 & 10 \\
& $\%$ & 50 & 50 & 100 \\
Group II & $\mathrm{N}$ & 4 & 6 & 10 \\
& $\%$ & 60 & 40 & 100 \\
Total & $\mathrm{N}$ & 9 & 11 & 20 \\
\multirow{3}{*}{ Chi-square } & $\%$ & 45 & 55 & 100 \\
& $\mathrm{X}^{2}$ & & 0.110 & \\
& $\mathrm{p}$-value & & 0.740 &
\end{tabular}

cally, there was difference in the mean of Child score being higher in the control group over the follow up period.

As regard the sequelae of liver cirrhosis, there were no significant differences between the two groups regarding the number of attacks of hematemesis, spontaneous bacterial peritonitis (SBP), hepatic encephalopathy, develop- 
ment of hepatocellular carcinoma (HCC) over the follow up period. One patient $(10 \%)$ who was subjected to the SCT developed hepatic focal lesion consistent with HCC after 4 months of the SCT for which conservative therapy was given (Child C) and the patient died 6 months later. Another patient (10\%) who was subjected to the SCT developed suprarenal mass after 6 months after the SCT. On the other hand two patients $(20 \%)$ of the control group developed HCC over the follow up period.

\section{Discussion}

Much has been written and rewritten on stem cells (SCs), their potentials, their properties, their possible uses and their risks (5). SC-based therapies could be used to cure inherited or genetic degenerative alterations associated with the loss of adult SC functions, such as cancers, immune system and hematopoietic disorders, cardiovascular, muscular and neurological diseases, gastrointestinal pathologies, diabetes and chronic hepatopathies. The manipulation of adult stem cells (ASCs) seems to be particularly promising, as it could improve the endogenous regenerative potential without risk of rejection and overcome the ethical and political issues related to embryonic stem cell research (11). Preliminary experience with clinical hepatocyte transplantation during the past decade has provided proof of concept that cell therapy can be effective for the treatment of some liver diseases. Recent progress in cell biology resulting in the isolation and characterization of bone marrow stem cells and progenitor cells further increases the expectation for a new approach to the treatment of genetic and chronic liver disease (12).

We hypothesized that infusion of HSCs may help to reverse liver failure in patients with decompensated cirrhosis manifested by improvement of the Child score. Thus, we conducted a human trial to evaluate safety and feasibility of autologous HSC transplantation in Egyptian patients with decompensated cirrhosis and to evaluate the outcome of HSC transplantation by assessing changes in, hepatic biochemical profile, Child score, liver size by abdominal ultrasonography and quality of life of the patients over the follow up period.

It is important to note that the patients of liver cirrhosis could respond to G-CSF treatment and that their white blood cell counts were increased in all cases, because this is a prerequisite for the remainder of the treatment protocol. However, the cell yields were lower than those expected from healthy donors. Also the patients tolerated well the sessions of leukapheresis with minimal side effects as have been mentioned in the results. This goes with agreement with Yannaki et al., who initiated a pilot study to assess the safety and efficacy of boost infusions of mobilized peripheral blood stem cells (PBSCs) in patients with advanced-stage alcoholic liver cirrhosis. Each of the two patients included in their study, safely underwent three rounds of mobilization, which were well tolerated in general (13).

In this study, there was improvement in the quality of life of all the studied patients especially over the first two months after the procedure. Such improvement may be related to the improvement of liver function. This goes with the trial of Mohamednejad et al., in which there was improvement in the quality of life of three patients of the four patients included in their study at the end of follow up (14).

In the current study, there was significant improvement in the mean serum albumin noticed after 15 days and 1 month after SCT in group I patients with improvement of the serum albumin level of about $0.5 \mathrm{gm} / \mathrm{dl}$. This goes with results of the trial of Gordon et al., in which 4 of the 5 patients included in their study showed improvement in the serum albumin of an average of $0.4 \sim 0.5$ $\mathrm{gm} / \mathrm{dl}$ (15). Although there was none significant statistical difference between the two groups regarding the serum albumin, the results of control groups were lower than the group I patients on the individual level reflecting the stem cells transplantation potential to improve the synthetic function of the diseased liver when compared to conventional treatment. At this stage, the mechanism of the effect on liver function is not fully understood but may reflect activation of genes corresponding to hepatocyte differentiation program in the transplanted stem cells upon exposure to the injured liver environment.

As regard the serum total bilirubin, there was statistically significant improvement in its level in patients of Group I after 1 month after SCT. There were statistically non significant improvements in the following months. Although the direct bilirubin, showed none significant differences between its level before and after the SCT in patients of group I, analysis on the individual level showed decrease in its levels in two patients of about $0.6 \sim 1 \mathrm{mg} / \mathrm{dl}$ over the first month and in another two patients over the six months of the follow up period. This also goes with the results of the study of Gordon et al., in which four of the five patients showed improvement in serum bilirubin which was maintained for up to 6 months (15).

As regard the liver enzymes (AST and ALT) there was statistically none significant difference in their levels before and after SCT in patients of group I, but there were statistically significant differences between the two groups re- 
garding the ALT level with significant lower levels in the patients of group I after 1 and 3 months after the stem cells transplantation. Also there was statistically significant difference as regard the AST level between the two groups after 1 month of the follow up period. Only one patient in the study of Gordon et al., showed decreased ALT and AST levels after the SCT (15). The decrease in the liver enzymes levels parallel the decrease in the inflammatory process and can be related to the regenerative properties of the stem cells.

$\gamma$-GT showed statistically significant decrease in its level in patients of Group I after 1 and 3 months after the SCT. Also there was statistically significant difference between the two groups regarding the $\gamma$-GT after 6 months after SCT with lower levels in the patients of Group I which can be explained by the improvement of hepatic inflammation.

The PT and INR which are important liver function tests that reflect the functional status of the liver showed none significant changes in their levels before and after the SCT in patients of Group I over the follow up period. Analyzing the results on the individual levels showed minimal and transient decrease in the level of the PT and INR for less than 1 month, which may be due to plasma transfusion and intravenous vitamin $\mathrm{K}$ injections, the patients received before and after the procedure for fear of bleeding tendency. Comparison between the two groups regarding the PT and INR showed none significant difference in their levels. Our results regarding the PT and INR are different from those of Mohamadnejad et al., who published results showing improvement in the PT in 2 of 3 patients in their study (14).

Ultrasound examination was done over the follow up period and revealed none significant differences regarding the liver size before and after the SCT. Also, there were none significant differences between the two groups regarding the liver size. One of our expectations was the increase in the liver size due to the regenerative properties of the stem cells that was not proved in our study. This may be due to the patients' advanced stage of liver cirrhosis (Child C stage) and suggests the possibility that SCT in earlier stages may have better outcome. The undetected changes in the liver size may also be due to lower potentiality of the abdominal ultrasound to detect the minor differences in the liver size as compared to the computerized tomography (CT) scan and magnetic resonant imaging (MRI) which are more accurate but are more expensive modalities with radiation and contrast risks of the CT.

G-CSF can induce spleen enlargement in peripheral blood cell donors and patients with hematologic malig- nancies (16), but this increase in spleen size very rarely may result in splenic rupture (17). Theoretically, the administration of G-CSF in patients with splenomegaly, as in cirrhotic patients, could increase the risk of splenic rupture. The splenic longitudinal diameters of patients of Group $I$ ranged from $16 \mathrm{~cm}$ to $22 \mathrm{~cm}$ before the G-CSF administration. Following up the size of the spleen after 15 days after the procedure in those patients showed statistically none significant difference. Fear of rupture spleen related to the use of G-CSF in patients of liver cirrhosis and splenomegaly was excluded in our study. This goes with the results of Gaia et al., who observed a significant reversible increase of splenic longitudinal diameter with no adverse event occurred in relation to G-CSF (18). They reported that splenomegaly up to $17 \mathrm{~cm}$ does not prevent safe bone marrow cell (BMC) mobilization following G-CSF in patients with end stage liver disease. The same conclusion was reached in the current study even in larger splenic sizes reaching $22.4 \mathrm{~cm}$. In a study done by Yannaki et al., G-CSF caused an increase in the spleen volume by $49 \%$ and $19.5 \%$ as compared to baseline value, in two of the three mobilization rounds in one patient, whereas the other patient had a $27 \%$ increase during the second round (13). It is possible that in conditions of chronic splenomegaly, the spleen becomes more flexible so that G-CSF priming may not result in abrupt changes in splenic size. In contrast, in a previously normal-sized spleen, G-CSF could cause striking enlargement over a short period of time, thus increasing the rupture potential. Consistent with this hypothesis, it has been shown that the median increase in spleen volume of mobilized healthy donors was significantly greater than mobilized patients with hematologic malignancies (85\% versus 57\%) (16).

There were none significant differences regarding the amount of the ascites of patients of Group I before and after the SCT, as assessed clinically by abdominal circumference measurement, body weight and abdominal sonar. This may be due to the complex pathophysiological mechanisms involved in the formation of the ascites, which were not reversed by the minimal improvement of the serum albumin level in the patients of group 1 after SCT. On the other hand, Terai et al., found that ascites improved after autologous bone marrow infusion (ABMI) therapy in their study which included 9 patients (19).

As regard the Child-Pugh score, there was statistically significant decrease in the score. One patient showed sustained decrease in the Child-Pugh score from 10 to 9 over the whole follow up period. The same occurred with another patient whose score decreased from 9 to 8 for more than 3 months. Although there were statistically none sig- 
nificant differences between the two groups regarding the Child-Pugh score, the mean values of the Child score were lower in patients of group I and continued to be inner the last range of disease state. In the study of Mohamednejad et al., one of the 4 patients showed improvement in the model for end stage liver disease (MELD) score(14). Another patient showed worsening of the MELD score at the end of the follow up period. In a study made by Terai et al., nine liver cirrhosis (LC) patients who received autologous bone marrow cell infusion (ABMI) from the peripheral vein showed significantly improved Child-Pugh scores at 4 and 24 weeks (19).

We found that SCT has not significantly affected the incidence of encephalopathy, hematemesis and SBP on comparing the two groups. Upper endoscopy showed none significant differences in the esophageal varices grades after 3 months after the SCT. One of the patients who received SCT developed HCC after 4 months of the SCT, while another patient developed suprarenal mass after 6 months after the SCT. Two patients of the control group developed HCC. It is suggested that embryonic stem cells (ESCs) may give rise to tumors, while cancers derived from adult stem cell (ASC) therapies haven't been reported. Nonetheless, the long-term safety of ASC infusion has not been adequately tested. Preclinical studies and clinical trials with longer follow up periods should be recommended prior to large-scale clinical applications of such cell-based therapies (5).

Five patients of Group I died within the first year of SCT on top of intractable attacks of hematemesis or hepatic coma. On the other hand, six patients of the control groups died within the first year of the follow up with none significant difference between the two groups regarding the death rate.

\section{Conclusion}

Hematopoietic Stem Cell transplantation for patients of liver cirrhosis on top of Hepatitis $\mathrm{C}$ virus infection is a safe and feasible procedure. It can improve the quality of life of cirrhotic patients, the hepatic functions such as serum albumin, bilirubin and also the Child score. This improvement is transient and lasts for about 3 to 6 months, or longer periods up to 12 months in other published studies. SCT had no effect on the life expectancy of the cirrhotic patients. It didn't affect the incidence of occurrence of complications related to the liver cirrhosis.

This means that SCT can be used as a bridging therapy till liver transplantation, which is the curative treatment, is available.

\section{Acknowledgement}

This work received no funds.

\section{Conflict of Interest}

The authors have no conflicting financial interest.

\section{References}

1. Sukhikh GT, Shtil AA. Stem cell transplantation for treatment of liver diseases: from biological foundations to clinical experience (review). Int J Mol Med 2003;11:395-400

2. Haydon GH, Neuberger J. Liver transplantation of patients in end-stage cirrhosis. Baillieres Best Pract Res Clin Gastroenterol 2000;14:1049-1073

3. Keeffe EB. Liver transplantation: current status and novel approaches to liver replacement. Gastroenterology 2001;120: 749-762

4. Rosen HR. Disease recurrence following liver transplantation. Clin Liver Dis 2000;4:675-689

5. Piscaglia AC. Stem cells, a two-edged sword: risks and potentials of regenerative medicine. World J Gastroenterol 2008; $14: 4273-4279$

6. Luk JM, Wang PP, Lee CK, Wang JH, Fan ST. Hepatic potential of bone marrow stromal cells: development of in vitro co-culture and intra-portal transplantation models. J Immunol Methods 2005;305:39-47

7. Jiang Y, Jahagirdar BN, Reinhardt RL, Schwartz RE, Keene $\mathrm{CD}$, Ortiz-Gonzalez XR, Reyes $M$, Lenvik $T$, Lund $T$, Blackstad M, Du J, Aldrich S, Lisberg A, Low WC, Largaespada DA, Verfaillie CM. Pluripotency of mesenchymal stem cells derived from adult marrow. Nature 2002; 418:41-49

8. Schächinger V, Erbs S, Elsässer A, Haberbosch W, Hambrecht R, Hölschermann H, Yu J, Corti R, Mathey DG, Hamm CW, Süselbeck T, Assmus B, Tonn T, Dimmeler S, Zeiher AM; REPAIR-AMI Investigators. Intracoronary bone marrow-derived progenitor cells in acute myocardial infarction. N Engl J Med 2006;355:1210-1221

9. Okumoto K, Saito T, Haga H, Hattori E, Ishii R, Karasawa T, Suzuki A, Misawa K, Sanjo M, Ito JI, Sugahara K, Saito K, Togashi H, Kawata S. Characteristics of rat bone marrow cells differentiated into a liver cell lineage and dynamics of the transplanted cells in the injured liver. J Gastroenterol 2006;41:62-69

10. Cholongitas E, Papatheodoridis GV, Vangeli M, Terreni N, Patch D, Burroughs AK. Systematic review: The model for end-stage liver disease--should it replace Child-Pugh's classification for assessing prognosis in cirrhosis? Aliment Pharmacol Ther 2005;22:1079-1089

11. Mimeault M, Hauke R, Batra SK. Stem cells: a revolution in therapeutics-recent advances in stem cell biology and their therapeutic applications in regenerative medicine and cancer therapies. Clin Pharmacol Ther 2007;82:252-264

12. Sakaida I, Terai S, Nishina H, Okita K. Development of cell therapy using autologous bone marrow cells for liver 
cirrhosis. Med Mol Morphol 2005;38:197-202

13. Yannaki E, Anagnostopoulos A, Kapetanos D, Xagorari A, Iordanidis F, Batsis I, Kaloyannidis P, Athanasiou E, Dourvas G, Kitis G, Fassas A. Lasting amelioration in the clinical course of decompensated alcoholic cirrhosis with boost infusions of mobilized peripheral blood stem cells. Exp Hematol 2006;34:1583-1587

14. Mohamadnejad M, Alimoghaddam K, Mohyeddin-Bonab M, Bagheri M, Bashtar M, Ghanaati H, Baharvand H, Ghavamzadeh A, Malekzadeh R. Phase 1 trial of autologous bone marrow mesenchymal stem cell transplantation in patients with decompensated liver cirrhosis. Arch Iran Med 2007; 10:459-466

15. Gordon MY, Levicar N, Pai M, Bachellier P, Dimarakis I, Al-Allaf F, M'Hamdi H, Thalji T, Welsh JP, Marley SB, Davies J, Dazzi F, Marelli-Berg F, Tait P, Playford R, Jiao L, Jensen S, Nicholls JP, Ayav A, Nohandani M, Farzaneh F, Gaken J, Dodge R, Alison M, Apperley JF, Lechler R, Habib NA. Characterization and clinical application of human CD34+ stem/progenitor cell populations mobilized into the blood by granulocyte colony-stimulating factor. Stem Cells 2006;24:1822-1830
16. Picardi M, De Rosa G, Selleri C, Scarpato N, Soscia E, Martinelli V, Ciancia R, Rotoli B. Spleen enlargement following recombinant human granulocyte colony-stimulating factor administration for peripheral blood stem cell mobilization. Haematologica 2003;88:794-800

17. Becker PS, Wagle M, Matous S, Swanson RS, Pihan G, Lowry PA, Stewart FM, Heard SO. Spontaneous splenic rupture following administration of granulocyte colony-stimulating factor (G-CSF): occurrence in an allogeneic donor of peripheral blood stem cells. Biol Blood Marrow Transplant 1997;3:45-49

18. Gaia S, Smedile A, Omedè P, Olivero A, Sanavio F, Balzola F, Ottobrelli A, Abate ML, Marzano A, Rizzetto M, Tarella C. Feasibility and safety of G-CSF administration to induce bone marrow-derived cells mobilization in patients with end stage liver disease. J Hepatol 2006;45:13-19

19. Terai S, Ishikawa T, Omori K, Aoyama K, Marumoto Y, Urata Y, Yokoyama Y, Uchida K, Yamasaki T, Fujii Y, Okita K, Sakaida I. Improved liver function in patients with liver cirrhosis after autologous bone marrow cell infusion therapy. Stem Cells 2006;24:2292-2298 